\title{
Grain-size effects on thermal properties of $\mathrm{BaTiO}_{3}$ ceramics
}

\author{
C J XIAO*, Z X LI and X R DENG \\ Department of Materials Science and Engineering, Henan University of Technology, Zhengzhou, China
}

MS received 5 January 2010

\begin{abstract}
Dense nanocrystalline $\mathrm{BaTiO}_{3}$ ceramics are successfully prepared by the high pressure assisted sintering. Microstructures are observed by scanning electronic microscopes. The grain sizes are estimated to be about 30 and $150 \mathrm{~nm}$. In comparison, $\mathrm{BaTiO}_{3}$ ceramics with the grain size of $600 \mathrm{~nm}$ and $1.5 \mu \mathrm{m}$ are fabricated by conventional pressure-less sintering. The thermal properties of $\mathrm{BaTiO}_{3}$ ceramics with different grain sizes are investigated by differential scanning calorimetry and thermal expansion. The results suggest that the enthalpy values for the tetragonal-cubic transition decreased and the thermal expansion values increased with decreasing grain size. Furthermore, the Curie temperature shifts to lower temperature with decreasing grain size.
\end{abstract}

Keywords. Nanocrystalline ceramics; thermal properties; size effect.

\section{Introduction}

$\mathrm{BaTiO}_{3}$ has been widely used in the electronic industry for its high dielectric constant and low losses above room temperature (Lines et al 1997). It is a typical $\mathrm{ABO}_{3}$ perovskite-type material with a variety of crystal structure modifications. Depending on the transition temperature, $\mathrm{BaTiO}_{3}$ have four kinds of crystal systems, that is, cubic, tetragonal, orthorhombic and rhombohedral. For single-crystal and polycrystalline $\mathrm{BaTiO}_{3}$, the phase transition temperatures are about 125.5 and $-90^{\circ} \mathrm{C}$, respectively. Interestingly, during the tetragonal-cubic transition, there is abnormal volume shrinkage with increasing temperature, so the phase transition can be verified according to this phenomenon. Recently, the size dependence on the polarization (Arlt et al 1985; Maria et al 2006), dielectric properties (Arlt et al 1985, Zhao et al 2004; Deng et al 2006a; Maria et al 2006; Wang et al 2006), crystal structure (Deng et al 2006b; Frey and Payne 2006; Xiao et al 2008), hardness (Deng et al 2008) of $\mathrm{BaTiO}_{3}$ ceramics has been widely studied in experimentally and theoretically (Lin et al 2006; Eliseev and Morozovska 2009). However, the research of thermal properties of $\mathrm{BaTiO}_{3}$ ceramics is scanty, especially in dense nanocrystalline grain samples, which depends strongly on the microstructure.

In this paper, using the pressure assisted sintering (PAS) and conventional pressure-less sintering (PLS), dense $\mathrm{BaTiO}_{3}$ ceramics with grain sizes of 30, 150, $600 \mathrm{~nm}$ and $1.5 \mu \mathrm{m}$ were successfully prepared. The thermal properties of nanocrystalline $\mathrm{BaTiO}_{3}$ ceramics

\footnotetext{
*Author for correspondence (cjxiao@haut.edu.cn)
}

compared with the different grain size specimens were discussed.

\section{Experimental}

In order to obtain dense nanocrystalline materials, very fine non-agglomerated powder with a narrow particle size distribution and an appropriate densification method to minimize the grain growth are required. In our experiment, the raw $\mathrm{BaTiO}_{3}$ powder with the grain sizes of 10 and $100 \mathrm{~nm}$ were synthesized by chemical processing (Li et al 2002). Dense $\mathrm{BaTiO}_{3}$ ceramics with grain sizes of $30 \mathrm{~nm}$ were obtained by PAS as described previously (Xiao et al 2008). A conventional PLS of the same raw $\mathrm{BaTiO}_{3}$ powders was also conducted for comparison. The mixed granules with PVA binder were formed into rectangular bars by uniaxially pressing and then compacted by cold isostatic pressing (CIP) at $200 \mathrm{MPa}$. The compacts were fired in a furnace at $1200^{\circ} \mathrm{C}$ for $2 \mathrm{~h}$ in air.

The microstructure of the sample was observed by scanning electron microscope (SEM, XL30-FEG) on fresh fracture surface. The grain sizes of $\mathrm{BaTiO}_{3}$ ceramics were determined with the linear intercept technique. The bulk density was determined using the Archimedes method. Differential scanning calorimetry (DSC, TA 2050DSC) measurements were made. The heating rate was $5^{\circ} \mathrm{C} / \mathrm{min}$. The dependence of phase transition behaviour on grain size was investigated for 15-20 mg specimens. Values for the enthalpy of transition were determined for the tetragonal-cubic transition. The thermal expansion curve was determined with a dilatometer (Theta Co., USA). The heating and cooling rates were $3^{\circ} \mathrm{C} / \mathrm{min}$ 

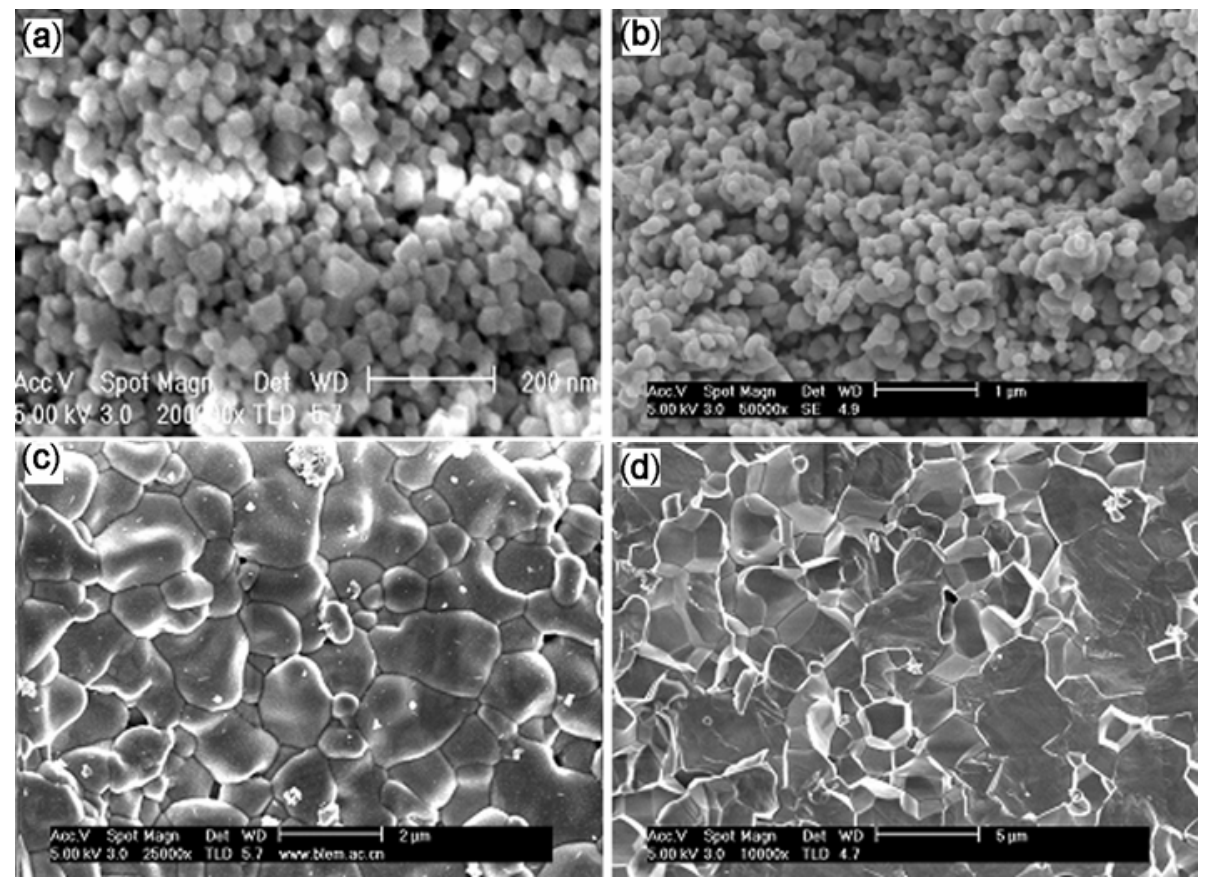

Figure 1. SEM photograph of $\mathrm{BaTiO}_{3}$ ceramics with various grain sizes (a) $30 \mathrm{~nm}$, (b) $150 \mathrm{~nm}$, (c) $600 \mathrm{~nm}$, (d) $1.5 \mu \mathrm{m}$.

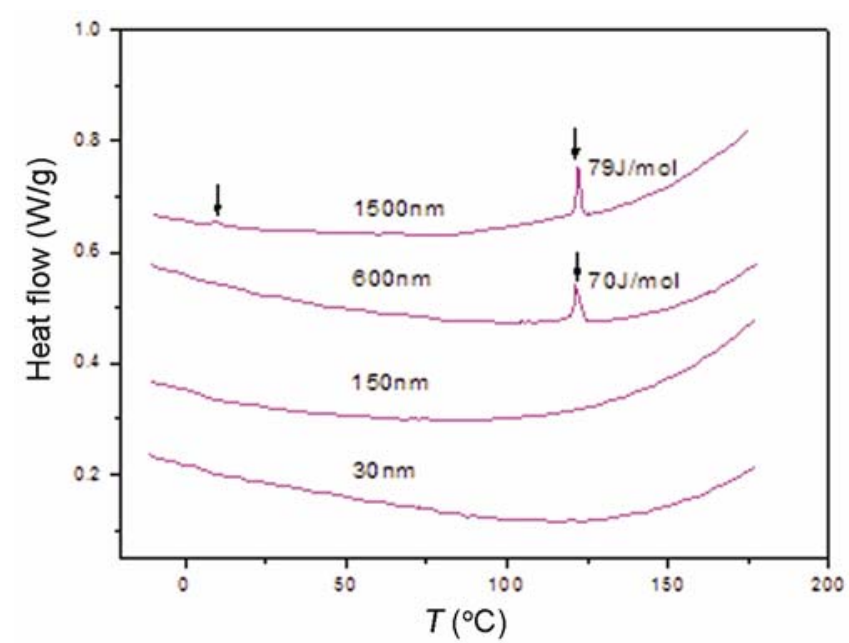

Figure 2. DSC data for of $\mathrm{BaTiO}_{3}$ ceramics with various grain sizes.

\section{Results and discussion}

Figure 1 shows SEM images of $\mathrm{BaTiO}_{3}$ ceramics sintered by PAS and PLS, respectively. Table 1 lists the processing conditions and the resultant properties of $\mathrm{BaTiO}_{3}$ ceramics in this study. Average grain sizes of $\mathrm{BaTiO}_{3}$ ceramics are approximately $30,150,600 \mathrm{~nm}$ and $1.5 \mu \mathrm{m}$ prepared by PAS and PLS, which the raw $\mathrm{BaTiO}_{3}$ powder were 10 and $100 \mathrm{~nm}$, respectively. Smaller grain size can be obtained by PAS under lower temperature and shorter hold time.

Figure 2 gives differential scanning calorimetry data recorded for $\mathrm{BaTiO}_{3}$ ceramics of various grain sizes with decreasing from 180 to $-10^{\circ} \mathrm{C}$. Endothermic features near 125 and $5^{\circ} \mathrm{C}$ for larger grain specimens are attributable to the first-order cubic-tetragonal and tetragonalorthorhombic transformations, respectively. Clearly, there are marked changes which take place in the transition behaviour for $\mathrm{BaTiO}_{3}$ ceramics with decreasing grain size. For $1.5 \mu \mathrm{m} \mathrm{BaTiO}_{3}$ ceramics, there are two exothermic peaks associated with the first-order orthorhombic-tetragonal and tetragonal-cubic transformations at approximately 10 and $122^{\circ} \mathrm{C}$, respectively. When the grain size decreased to $600 \mathrm{~nm}$, only a exothermic peak associated with the tetragonal-cubic transformations exists at about $120^{\circ} \mathrm{C}$. When the grain size further decreased to 150 and even $30 \mathrm{~nm}$, the features associated with the two formerly independent transitions are lost. The enthalpy values for the tetragonal-cubic transition ranged from $79 \mathrm{~J} / \mathrm{mol}$ for the $1.5 \mu \mathrm{m}$ grain size to $70 \mathrm{~J} / \mathrm{mol}$ for the $600 \mathrm{~nm}$ grain size, which compares closely with reported $\mathrm{BaTiO}_{3}$ polycrystalline values. A reduction in transition enthalpy is reasonable for material exhibiting suppressed transition characteristics (Frey et al 2006). In addition, for $1.5 \mu \mathrm{m} \mathrm{BaTiO}_{3}$ ceramics, the phase transition temperature for orthorhombic-tetragonal and tetragonal-cubic transformations were about 10 and $122^{\circ} \mathrm{C}$, while the phase transition temperature for tetragonal-cubic transformations were about $120^{\circ} \mathrm{C}$ for $600 \mathrm{~nm} \mathrm{BaTiO}{ }_{3}$ ceramics. The cubic-tetragonal transition shift to lower temperatures with decreasing grain size, as has been concluded previously based on dielectric constant data (Arlt et al 1985; Zhao et al 2004; Deng et al 2006a; Maria et al 2006; Wang et al 2006). 
Table 1. Processing conditions and the resultant properties of $\mathrm{BaTiO}_{3}$ ceramics.

\begin{tabular}{rcccc}
\hline $\begin{array}{l}\text { Grain size } \\
(\mathrm{nm})\end{array}$ & $\begin{array}{c}\text { Sintering } \\
\text { condition }\end{array}$ & $\begin{array}{c}\text { Sintering } \\
\text { temperature }\left({ }^{\circ} \mathrm{C}\right)\end{array}$ & $\begin{array}{c}\text { Relative } \\
\text { density }(\%)\end{array}$ & $\begin{array}{c}\text { Mean linear expansion } \\
\text { coefficient }\left({ }^{-6} /{ }^{\circ} \mathrm{C}\right)\end{array}$ \\
\hline 30 & PAS & 1000 & $96 \cdot 2$ & $7 \cdot 31$ \\
150 & PAS & 1000 & $95 \cdot 7$ & $5 \cdot 16$ \\
600 & PLS & 1200 & $97 \cdot 7$ & $3 \cdot 27$ \\
1500 & PLS & 1200 & $98 \cdot 1$ & $2 \cdot 28$ \\
\hline
\end{tabular}
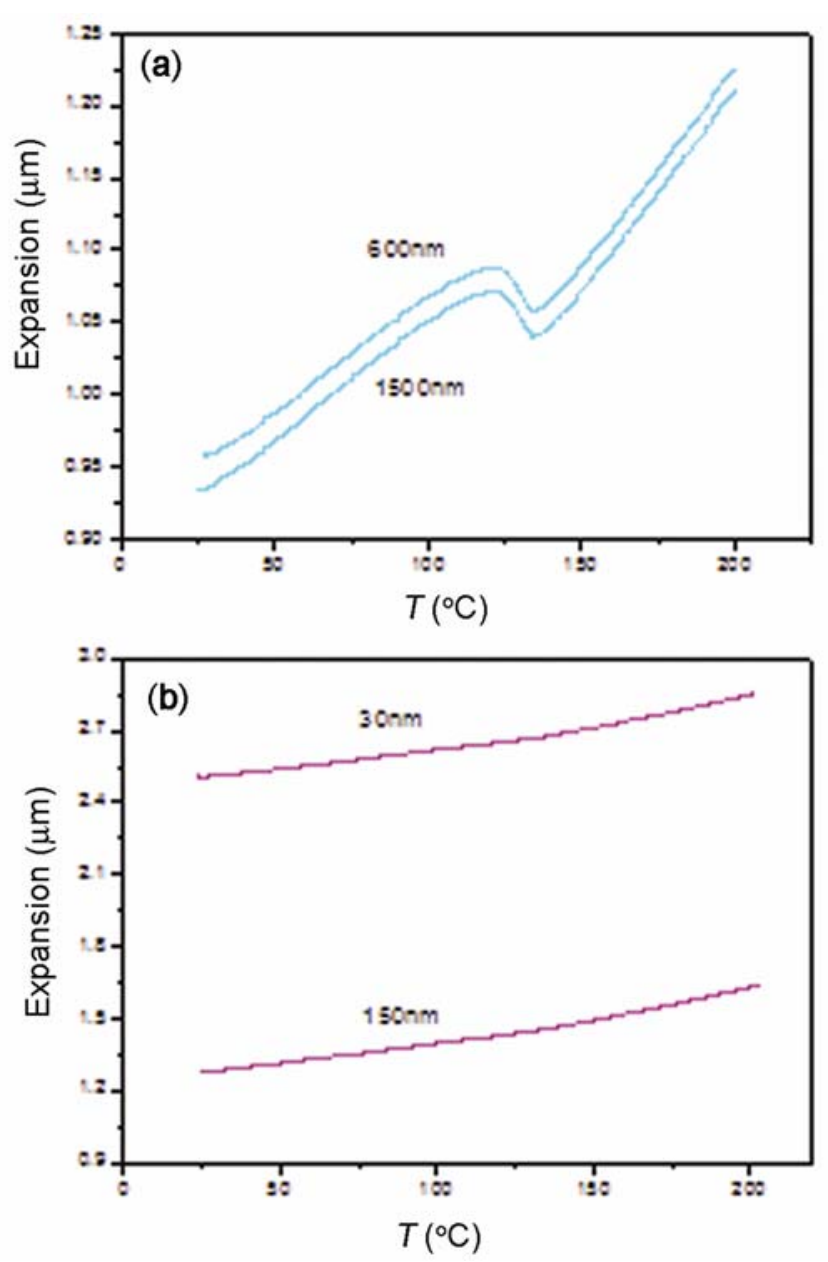

Figure 3. The thermal expansion curves of $\mathrm{BaTiO}_{3}$ ceramics with various grain sizes. (a) $600 \mathrm{~nm}$ and $1.5 \mu \mathrm{m}$, (b) 150 and $30 \mathrm{~nm}$.

The linear thermal expansion curves for $\mathrm{BaTiO}_{3}$ ceramics of various grain sizes with increasing from room temperature to $200^{\circ} \mathrm{C}$ are shown in figure 3. With temperature increasing, there is clear shrinkage in $600 \mathrm{~nm}$ and $1.5 \mu \mathrm{m} \mathrm{BaTiO}_{3}$ ceramics in figure $3(\mathrm{~b})$. The abnormal volume changes associated with the phase transition between tetragonal and cubic as the transition taking place. The phase transition temperatures are both about between 123 and $136^{\circ} \mathrm{C}$. In contrast, we can not see any change in 150 and $30 \mathrm{~nm} \mathrm{BaTiO}{ }_{3}$ ceramics in figure 3(a). The features associated with the transition disappeared.
This result is highly similar to those above reported of DSC data. The mean coefficients of linear thermal expansion are listed in table 1. From the table, it is clear seen that the value increased with decreasing grain size. As we all know, materials expand because an increase in temperature leads to greater thermal vibration of the atoms in a material, and hence to an increase in the average separation distance of adjacent atoms. Compared with the coarse-grained specimens, the presence of the large stress in fine-grained $\mathrm{BaTiO}_{3}$ ceramics (Zhao et al 2004; Buessem et al 1966; Lin et al 2006) is one of the main factors. With increasing temperature, the stress gradually relieve, so that the linear thermal expansions of the fine-grained specimens are bigger than those of the coarse-grained specimens. Of course, the characters of nano-sized materials, such as high surface area and high degree of defects, may also play an important role.

\section{Conclusions}

Dense $\mathrm{BaTiO}_{3}$ ceramics were successfully prepared by PAS and PLS. Microstructures are observed by scanning electronic microscopes. The grain sizes are estimated to be about $30,150,600 \mathrm{~nm}$ and $1.5 \mu \mathrm{m}$. The thermal properties of $\mathrm{BaTiO}_{3}$ ceramics with different grain sizes were investigated by differential scanning calorimetry and thermal expansion method. The results suggest that the enthalpy values for the tetragonal-cubic transition decrease and the values for thermal expansion increase with decreasing grain size. Furthermore, the Curie temperature shifts up lower temperature with decreasing grain size. These differences of the thermal behaviour between $\mathrm{BaTiO}_{3}$ ceramics are attributed to the variation of the resultant microstructure, especially the grain size of the ceramics.

\section{Acknowledgement}

This work was supported by Henan University of Technology of China through research project 2007BS012.

\section{References}

Arlt G, Hennings D and De G 1985 J. Appl. Phys. 5815

Buessem W R, Cross L E and Goswami A K 1966 J. Am. Ceram. Soc. 4933 
Deng X Y et al 2006a Appl. Phys. Lett. 88252905

Deng X Y et al 2006b J. Am. Ceram. Soc. 891050

Deng X Y et al 2008 J. Electroceram. 21238

Eliseev E A and Morozovska A N 2009 J. Mater. Sci. 445149

Frey M H and Payne D A 1996 Phys. Rev. B54 3158

Li B R, Wang X H and Li L T 2002 Mater. Chem. Phys. 78 292
Lin S et al 2006 Phys. Rev. B74 134115

Lines M E and Glass A M 1977 Principles and applications of ferroelectrics and related phenomena (Oxford: Clarendon Press) Maria T et al 2006 Phys. Rev. B73 064114

Wang X H et al 2006 Appl. Phys. Lett. 89162902

Xiao C J, Jin C Q and Wang X H 2008 Mater. Chem. Phys. 111209

Zhao Z et al 2004 Phys. Rev. B70 024107 